\title{
Studies on Heterosis and Combining Ability in Rice (Oryza sativa L.) for Morpho-Physiological Traits under Normal and Saline Conditions
}

\author{
Archana Devi, Preeti Kumari, Ranjan Dwivedi, Saket Dwivedi, O.P. Verma, \\ P.K. Singh and D.K. Dwivedi*
}

Department of Genetics and Plant Breeding, Department of Plant Molecular Biology and Genetic Engineering, N. D. University of Agriculture and Technology, Kumarganj,

\author{
Faizabad - 224229 - Uttar Pradesh, India \\ *Corresponding author
}

\section{A B S T R A C T}

\section{Keywords}

Standard

heterosis,

Combining

ability,

Morphological

traits and rice.

Article Info

Accepted:

17 June 2017

Available Online:

10 August 2017
An experiment was conducted to evaluate the performance of $54 \mathrm{~F}_{1}$ developed by crossing of 18 lines with 3 testers. Analysis of variance revealed highly significant difference in treatments, parents, crosses and line $\times$ tester for days to $50 \%$ flowering, plant height, flag leaf area and grain yield per plant under both normal and saline conditions. Parent $v s$. crosses were highly significant for plant height and grain yield per plant while significant for days to $50 \%$ flowering and flag leaf area in normal condition but in case of saline condition highly significant differences were found for plant height and flag leaf area and non-significant for days to 50\% flowering and grain yield per plant. Analysis of variance revealed highly significant differences among lines for grain yield per plant under both normal and saline conditions while plant height for saline condition. Tester was nonsignificant for all the characters under both normal and saline conditions. The estimates of variance of specific combining ability effects, ratio of variance of general combining ability to specific combining ability and degree of dominance indicated preponderance of non-additive gene effects for each trait. On over all bases, role of lines in the expression of most of the morphological traits were more than testers and line $\times$ tester interaction under both conditions.

\section{Introduction}

Rice is the seed of the grass species Oryza sativa L. (Asian rice) or Oryza glaberrima (African rice). As a cereal grain, it is the most widely consumed staple food for a large part of the world's human population, especially in Asia. It is the agricultural commodity with the third-highest worldwide production (rice, 741.5 million tonnes in 2014), after sugarcane (1.9 billion tonnes) and maize (1.0 billion tonnes). India is the world's second largest producer of rice, wheat and other cereals. The huge demand for cereals in the global market is creating an excellent environment for the export of Indian cereal products. According to the final estimate for the year 2014-15 by Ministry of Agriculture of India, the production of rice stood at 105.48 million tonnes. (According to APDEA report, 2016).

The high food quantities of rice grain at one hand, and the intensive growth of population in the developing countries on the other, have predetermined the wide cultivation of this 
crop practically in all situations including saline-alkali soils. However, considering the current rate of population growth at the global level and in our country, the requirement of rice by $2020 \mathrm{AD}$ is estimated to be around 800 million tonnes and 140 million tonnes, respectively. This increased productivity of rice therefore, must come from less land, water, labour and other inputs. This reducing trend of agricultural land availability would be overcome with utilization of an area estimated at more than $22 \mathrm{~m}$ ha in Asia alone. Both saline and alkali soils are wide spread in inland areas as that in U.P.

Line $\times$ tester method (Kempthorne, 1957) is useful in deciding the relative aptitude of female and male lines to produce desirable hybrid combinations. It also provides information on genetic components and enables the breeder to choose appropriate breeding methods for plant type development programme.

Information on general and specific combining ability for plant type is helpful in selection of suitable parents for the development of hybrids with ideal plant type. A large number of morpho-physiological characters are known to be affected by ecological factors. In breeding programmes, it is often difficult to combine ideal traits, therefore, the measurement of genetic variation and understanding of mode of inheritance of quantitative traits are essential steps in any crop improvement programme. Heritability estimates provide authentic information about a particular genetic attribute which will be transmitted to the consecutive generations. A broad-sense heritability estimate provides information on the relative magnitude of genetic and environmental variation in the population and help breeders to determine the possible extent for improvement through selection. Again the heritable portion of the total variation might not be always due to additive gene action. Thus, estimates of heritability alone give no clear indication of the associating genetic progress that would result from selecting the best plants. It is also essential to find out the relative magnitude of additive and nonadditive genetic variances with regard to the characters of concern. The heritability along with phenotypic variance and the selection intensity, however, promise the estimation of genetic advance or response to selection which is more useful in the selection of promising lines. Therefore, considering all these facts the present investigation was under taken to work out the nature and magnitude to inheritance of morpho-physiological traits.

\section{Materials and Methods}

The present investigation was conducted at Genetics and Plant Breeding Research Farm and Student Instructional Farm of N.D. University of Agriculture and Technology, Narendra Nagar (Kumarganj), Faizabad. The crosses were made during Kharif, 2013 and the hybrids along with parental lines and checks were evaluated during Kharif, 2014.

A line $\times$ tester set of 54 hybrids $\left(F_{1} s\right)$ were derived by crossing 18 lines (female) with three diverse high yielding testers (male) viz., Narendra Usar Dhan-2, Narendra Usar Dhan3 and Narendra Usar Dhan 2009 during Kharif 2013. The eighteen lines were NDRK5014, NDRK-5016, NDRK-5030, NDRK5032, NDRK-5035, NDRK-5043, NDRK5062, NDRK-5071, NDRK-5081, NDRK5092, NDRK-50001, CSR - 23, CSR - 28, IR SST-N 27, IR 74095 AC 64, IR 72579-B-2R, HPU-CIJ, and LD 183-4. The $54 \mathrm{~F}_{1} \mathrm{~s}$ along with their parents and check varieties (NDR 359 for normal condition and Narendra Usar Dhan 2009 for saline condition) were evaluated in randomized complete block design with three replications during Kharif, 2014. Single row plots of $3 \mathrm{~m}$ length were 
used for transplanting single seedling per hill for each genotype (treatment) in each replication following intra and inter-row spacing of $15 \mathrm{~cm}$ and $20 \mathrm{~cm}$, respectively. Recommended cultural practices were followed to raise a good crop.

The $\mathrm{pH}, \mathrm{EC}$ and ESP were $8.9,0.28 \mathrm{dSm}^{-1}$ and $68 \%$, respectively for saline soil. The data were recorded on morpho-physiological traits like days to 50\% flowering, plant height $(\mathrm{cm})$, flag leaf area $\left(\mathrm{cm}^{2}\right)$ and grain yield per plant $(\mathrm{g})$. The analysis of variance for randomized complete block design was carried out following Panse and Sukhatme (1967). The combining ability analysis was carried out following line $\times$ tester mating design outlined by Kempthorne (1957) and further elaborated by Arunachalam (1974). Line $\times$ tester analysis was used to estimate general combining ability (GCA) and specific combining ability (SCA) variances and their effects using the observations taken on $F_{1}$ generation of the line $\times$ tester sets of crosses. In this mating system, a random sample of ' 1 ' lines is taken and each line is mated to each of the ' $t$ ' testers (Singh and Chaudhary, 1985). Phenotypic (PCV) and genotypic (GCV) coefficients of variation for different characters were estimated by following formulae suggested by Burton and de Vane (1953). Heritability in broad sense $\left(h^{2} b\right)$ was calculated as suggested by Hanson et al., (1956). The expected genetic advance $(\mathrm{Ga})$ was estimated using formula suggested by Johnson et al., (1955). The standard heterosis was computed as per cent increase or decrease of the mean values of crosses $\left(\mathrm{F}_{1}\right.$ 's $\left.\mathrm{s}\right)$ over standard variety as suggested by Fonseca and Patterson (1968).

\section{Results and Discussion}

Analysis of variance revealed highly significant differences in treatment, parent, crosses and line $\times$ tester for days to $50 \%$ flowering, plant height, flag lead area and grain yield per plant under both normal and saline conditions. Parent vs. crosses were highly significant for plant height and grain yield per plant while significant for days to $50 \%$ flowering and flag leaf area in normal condition but in case of saline condition highly significance were found for plant height and flag leaf area and non-significant for days to 50\% flowering and grain yield per plant. Analysis of variance revealed highly significant differences among lines for grain yield per plant under both conditions, while, plant height for saline condition. Tester was non-significant for all the characters under both normal and saline conditions. The success of selection in improving quality characters depends mainly on presence of substantial genetic variability and nature of heritability and genetic advance. The genetic variability is the raw material of plant breeding programme on which selection acts to evolve superior genotypes.

Estimates of SCA variance were higher than the corresponding estimates of GCA variance for all the traits under both conditions. The analysis of variance for combining ability revealed no significant differences among the testers for all the characters under study. The mean sum of squares due to lines $x$ tester interactions was found to be highly significant for all the characters representing importance of specific combining ability and non-additive gene action. The above results suggested importance of both additive and non-additive gene effects for morphological traits.

The phenotypic and genotypic coefficients of variation can be used for assessing and comparing the nature and magnitude of variability existing for different characters in the breeding materials. Heritability in broad sense quantifies the proportion of heritable genetic variance to total phenotypic variance, while heritability in narrow sense represents the ratio of fixable additive genetic variance 
to total phenotypic variance. Estimates of heritability help in estimating expected progress through selection. The genetic advance in per cent of mean provides indication of expected selection response by taking into account the existing genetic variability and heritability of the characters. The estimates of direct selection parameters, coefficients of variation, heritability and genetic advance in per cent of mean were computed for four characters of 54 crosses and their parents (Tables 1 and 2 for normal and saline conditions, respectably).

In normal condition, none of the character having high estimates for genotypic and phenotypic coefficient of variation, heritability in broad sense along with genetic advance in per cent of mean. Days to $50 \%$ flowering were recorded moderate heritability estimates, while, low for GCV, PCV and genetic advance in per cent of mean. Plant height showed moderate estimates for PCV and GCV, while, high estimates for heritability and genetic advance in per cent of mean.

Flag leaf area showed moderate estimates for GCV, while, high for PCV, heritability in broad sense and genetic advance in per cent of mean. Grain yield per plant were recorded with high estimates of heritability and genetic advance in per cent of mean and moderate for PCV and GCV.

Under saline condition, days to $50 \%$ flowering were recorded low estimates for all the genetic parameters like PCV, GCV, heritability in broad senesce and genetic advance in per cent of mean. Plant height showed high for heritability in broad senesce, moderate for PCV and genetic advance in per cent of mean, while, low estimates for GCV. Flag leaf area showed high estimates for PCV and heritability, moderate for genetic advance in per cent of mean, while in case of GCV low estimates was recorded. Grain yield per plant were recorded high estimates for heritability and genetic advance in per cent of mean and moderate for PCV and GCV. The low to high estimates of direct selection parameters for above mentioned characters indicated that traits with high estimates are ideal for improvement through selection in context of materials evaluated due to existence of high genetic variability represented by high coefficients of variation and high transmissibility denoted by high heritability for them. Traits with low estimates of selection parameters indicated that improving through selection in context of present material would be difficult due to lack of genetic variability for these traits. The high estimates of direct selection parameters observed for the above characters are broadly in agreement with earlier reports in rice (Basavaraja et al., 2013 and Sathya and Jebaraj, 2013 Kumari et al., 2017).

Proportional contribution of lines, testers and lines $\times$ testers interaction for 4 characters have been presented in table 1 for normal condition and in table 2 for saline condition. The maximum contribution of females (lines) was recorded for grain yield per plant (56.12\%) followed by plant height $(36.76 \%)$, days to $50 \%$ flowering (28.22\%) and flag leaf area $(20.67 \%)$ for normal condition. Under saline condition the maximum contribution of females (lines) was recorded for grain yield per plant $(59.48 \%)$ followed plant height $(48.05 \%)$, flag leaf area $(31.95 \%)$ and days to $50 \%$ flowering (26.16\%).

Maximum contribution of male (testers) in normal condition was recorded for flag leaf area $(8.10 \%)$ followed by plant height (3.98\%), days to $50 \%$ flowering $(2.11 \%)$ and grain yield per plant $(1.42 \%)$, while in saline condition maximum contribution of male lines (testers) was recorded for days to $50 \%$ flowering $(10.30 \%)$ followed by flag leaf area 
(3.33\%), grain yield per plant $(2.20 \%)$ and plant height $(1.15 \%)$. Proportional contribution of lines $\times$ testers was found maximum for the flag leaf area $(71.22 \%)$ followed by days to $50 \%$ flowering $(69.65 \%)$, plant height $(59.25 \%)$ and grain yield per plant (42.45\%) under normal condition.

Proportional contribution of lines $\times$ testers was found maximum for the character flag leaf area $(64.72 \%)$ followed by days to $50 \%$ flowering (63.55\%), plant height (50.79\%) and grain yield per plant(38.32\%) under saline condition.

Selection of parents on the basis of mean performance and general combining ability (GCA) effects

Mean performance and GCA effects of the parents have been given in table 3 for normal and in table 4 for saline conditions.

The significant and positive GCA effects for grain yield per plant were exhibited by NDRK 5014, NDRK 5035, NDRK 5071, NDRK 50001, CSR - 28, IR 74095AC -64, IR 72579-2-2R, HPU-CIJ and LD 183-4 among line and by Narendra Usar Dhan-2 among testers.

The parent NDRK 5014 and HPU-CIJ with highest GCA effects for grain yield per plant also showed significant and desirable GCA effects for flag leaf area.

Line NDRK 5035, NDRK 50001 and LD 183-4 emerged as good general combiner for plant height and flag leaf area. NDRK 5071 emerged as good general combiner for days to $50 \%$ flowering while in case of tester Narendra Usar Dhan 2 showed highly significant and positive GCA effects for grain yield per plant also showed significant and desirable GCA effects for plant height and flag leaf area under normal condition.
The significant and positive GCA effects for grain yield per plant were exhibited by NDRK 5014, NDRK 5016, NDRK 5035, NDRK 50001, CSR 28, IR 74095AC -64, HPU-CIJ and LD 183-4 among line and by Narendra Usar Dhan-3 among testers.

The parent NDRK 5014 and NDRK 50001 with highest GCA effects for grain yield per plant also showed significant and desirable GCA effects for days to $50 \%$ flowering and plant height. Line NDRK 5016, NDRK 5035, HPU-CIJ and LD 183-4 with highest GCA effects for grain yield per plant also showed significant and desirable GCA effects for days to 50\% flowering, plant height and flag leaf area. Line CSR 28 emerged as good general combiner for days to $50 \%$ flowering while in case of tester Narendra Usar Dhan 3 exhibited highly significant and positive GCA effects for grain yield per plant also showed significant and desirable GCA effects for days to $50 \%$ flowering under saline condition.

The nine parents for normal and eight parents for saline conditions showing positive and significant GCA effects for grain yield and other important morpho-physiological traits as mentioned above may serve as valuable parents for hybridization programme or multiple crossing programme for obtaining high yielding hybrid varieties with ideal plant type. Dwivedi et al., (1999) have also reported Narendra 359 and Sarjoo 52 as good general combiner for yield and morphological traits over environments.

Selection of hybrids on the basis of specific combining ability (SCA) effects, mean performance and standard heterosis

The SCA effects represent dominance and epistasis gene actions and can be used as an index to determine the worth of a particular cross combination in the utilization as hybrids. 
Table.1 Mean square for analysis of variance, estimates of genetic components and contribution of line, tester and line $\times$ tester to the total Variance in rice genotypes under normal condition

\begin{tabular}{|c|c|c|c|c|c|}
\hline Source & d.f. & $\begin{array}{l}\text { Days to } 50 \% \\
\text { flowering }\end{array}$ & $\begin{array}{l}\text { Plant height } \\
(\mathrm{cm})\end{array}$ & Flag leaf area $\left(\mathrm{cm}^{2}\right)$ & $\begin{array}{l}\text { Grains yield per } \\
\text { plant }(g)\end{array}$ \\
\hline Replication & 2 & 6.16 & 3.52 & 1.32 & 0.5 \\
\hline Treatment & 74 & $39.49 * *$ & $336.21 * *$ & $58.31 * *$ & $36.48 * *$ \\
\hline Parents & 20 & $38.32 * *$ & $277.43^{* *}$ & $40.48 * *$ & $18.92 * *$ \\
\hline Parent vs crosses & 1 & $40.13 *$ & $1351.41 * *$ & $6.77 *$ & $11.62 * *$ \\
\hline Crosses & 53 & $29.34 * *$ & $339.23 * *$ & $66.01 * *$ & $43.57 * *$ \\
\hline Line & 17 & 35.32 & 388.78 & 42.54 & $76.24 * *$ \\
\hline Tester & 2 & 22.51 & 358.18 & 141.68 & 16.43 \\
\hline $\mathbf{L} \times \mathbf{T}$ & 34 & $43.57 * *$ & $313.34 * *$ & $73.28 * *$ & $28.83 * *$ \\
\hline Error & 148 & 6.45 & 3.26 & 3.84 & 1.47 \\
\hline$\sigma^{2} \mathrm{GCA}$ & & -0.04 & 0.28 & 0.05 & 0.16 \\
\hline$\sigma^{2} \mathrm{SCA}$ & & 9.26 & 115.69 & 7.64 & 12.42 \\
\hline$\sigma^{2} \mathrm{GCA} / \sigma^{2} \mathrm{SCA}$ & & -0.004 & 0.002 & 0.006 & 0.01 \\
\hline$\sigma^{2} \mathrm{~A}$ & & -0.074 & 0.553 & 0.095 & 0.315 \\
\hline$\sigma^{2} D$ & & 9.256 & 115.689 & 7.635 & 12.418 \\
\hline$\left(\sigma^{2} A / \sigma^{2} D\right)^{1 / 2}$ & & 0.089 & 0.07 & 0.109 & 0.0127 \\
\hline PCV & & 4.57 & 11.75 & 20.02 & 14.74 \\
\hline GCV & & 3.63 & 11.58 & 18.19 & 13.89 \\
\hline $\mathbf{h}_{(\text {(b.s.) }}^{2} \& \pm \mathrm{SE}$ & & $63.06 \pm 2.07$ & $97.15 \pm 1.47$ & $82.53 \pm 1.60$ & $88.78 \pm 0.99$ \\
\hline GA & & 5.93 & 23.52 & 33.96 & 26.95 \\
\hline Contribution \% of Lines & & 28.22 & 36.76 & 20.67 & 56.12 \\
\hline Testes & & 2.11 & 3.98 & 8.1 & 1.42 \\
\hline Line $\times$ Tester & & 69.65 & 59.25 & 71.22 & 42.45 \\
\hline
\end{tabular}

*,** Significant at $5 \%$ and $1 \%$ probability levels, respectively 
Table.2 Mean square for analysis of variance, estimates of genetic components and contribution of line, tester and line $\times$ tester to the total Variance in rice genotypes under saline condition

\begin{tabular}{|c|c|c|c|c|c|}
\hline Source & d.f. & $\begin{array}{r}\text { Days to } 50 \% \\
\text { flowering } \\
\end{array}$ & Plant height $(\mathrm{cm})$ & $\begin{array}{r}\text { Flag leaf area } \\
\left(\mathrm{cm}^{2}\right)\end{array}$ & $\begin{array}{r}\text { Grains yield per plant } \\
(\mathrm{g})\end{array}$ \\
\hline Replication & 2 & 8.62 & 4.84 & 1.06 & 2.48 \\
\hline Treatment & 74 & $39.71 * *$ & $163.66 * *$ & $41.64 * *$ & $50.56^{* *}$ \\
\hline Parents & 20 & $20.31 * *$ & $110.16^{* *}$ & $23.18 * *$ & $46.36^{* *}$ \\
\hline Parent vs crosses & 1 & 0.01 & $686.59 * *$ & $43.65 * *$ & 0.65 \\
\hline Crosses & 53 & $47.78 * *$ & $173.98 * *$ & $48.56 * *$ & $53.09 * *$ \\
\hline Line & 17 & 38.96 & $260.66^{*}$ & 48.37 & $98.45^{*}$ \\
\hline Tester & 2 & 130.36 & 53.17 & 42.8 & 31 \\
\hline $\mathbf{L} \times \mathbf{T}$ & 34 & $47.33 * *$ & $137.74 * *$ & $49.00 * *$ & $31.71 * *$ \\
\hline Error & 148 & 7.63 & 3.7 & 2.45 & 1.36 \\
\hline$\sigma^{2} \mathrm{GCA}$ & & 0.005 & 0.387 & 0.044 & 0.229 \\
\hline$\sigma^{2} \mathrm{SCA}$ & & 21.511 & 47.489 & 5.48 & 16.597 \\
\hline$\sigma^{2} \mathrm{GCA} / \sigma^{2} \mathrm{SCA}$ & & 0.0002 & 0.0081 & 0.0080 & 0.014 \\
\hline$\sigma^{2} A$ & & 0.01 & 0.775 & 0.088 & 0.457 \\
\hline$\sigma^{2} \mathrm{D}$ & & 21.51 & 47.49 & 5.48 & 16.597 \\
\hline$\left(\sigma^{2} A / \sigma^{2} D\right)^{1 / 2}$ & & 0 & 0.126 & 0.126 & 0.014 \\
\hline PCV & & 4.35 & 10.83 & 58.35 & 19.65 \\
\hline GCV & & 3.32 & 9.5 & 5.23 & 18.88 \\
\hline $\mathbf{h}_{(\text {b.s. })}^{2} \& \pm \mathrm{SE}$ & & $9.07 \pm 2.26$ & $76.94 \pm 1.57$ & $93.51 \pm 1.28$ & $92.34 \pm 0.95$ \\
\hline GA & & 8.78 & 17.17 & 17.48 & 37.32 \\
\hline Contribution \% of Lines & & 26.16 & 48.05 & 31.95 & 59.48 \\
\hline Testes & & 10.3 & 1.15 & 3.33 & 2.2 \\
\hline Line $\times$ Tester & & 63.55 & 50.79 & 64.72 & 38.32 \\
\hline
\end{tabular}

$*, * *$ Significant at $5 \%$ and $1 \%$ probability levels, respectively 
Table.3 Mean performance and general combining ability (GCA) effects of parents (lines and testers) for Morphology and yield in rice under normal condition

\begin{tabular}{|c|c|c|c|c|c|c|c|c|c|}
\hline \multirow[t]{2}{*}{ S.N. } & \multirow[t]{2}{*}{ Line } & \multicolumn{2}{|c|}{$\begin{array}{r}\text { Days to } 50 \% \\
\text { flowering }\end{array}$} & \multicolumn{2}{|c|}{ Plant height $(\mathrm{cm})$} & \multicolumn{2}{|c|}{ Flag leaf area $\left(\mathrm{cm}^{2}\right)$} & \multicolumn{2}{|c|}{ Grains yield / plant $(g)$} \\
\hline & & MEAN & GCA & MEAN & GCA & MEAN & GCA & MEAN & GCA \\
\hline 1 & NDRK-5014 & 93.67 & 0.59 & 99.02 & 0.75 & 21.22 & $4.53 * *$ & 25.29 & $2.16^{* *}$ \\
\hline 2 & NDRK-5016 & 94.00 & 1.37 & 87.15 & 0.72 & 16.02 & -0.07 & 21.57 & $-0.97 *$ \\
\hline 3 & NDRK-5030 & 91.67 & 0.59 & 84.42 & $-3.19 * *$ & 33.16 & $-1.52 *$ & 24.47 & $-5.99 * *$ \\
\hline 4 & NDRK-5032 & 97.67 & 0.70 & 96.28 & $-9.37 * *$ & 26.00 & $-2.24 * *$ & 14.23 & 0.55 \\
\hline 5 & NDRK-5035 & 87.33 & -0.19 & 87.35 & $12.93 * *$ & 20.65 & $1.61 *$ & 23.2 & $1.37 * *$ \\
\hline 6 & NDRK-5043 & 92.00 & $-6.30 * *$ & 75.22 & $-6.17 * *$ & 19.41 & 0.04 & 18.8 & $-2.51 * *$ \\
\hline 7 & NDRK-5062 & 93.33 & -1.30 & 76.75 & $-2.86 * *$ & 19.12 & 0.10 & 23.71 & $-3.91 * *$ \\
\hline 8 & NDRK-5071 & 91.33 & $3.48^{* *}$ & 77.95 & -0.71 & 20.23 & $-3.21 * *$ & 26 & $2.73 * *$ \\
\hline 9 & NDRK-5081 & 92.67 & -0.96 & 85.62 & 0.67 & 24.54 & $1.36^{*}$ & 26.16 & $-1.34 * *$ \\
\hline 10 & NDRK-5092 & 87.00 & 0.26 & 113.48 & $4.60 * *$ & 30.60 & $-3.66 * *$ & 24.17 & $-1.32 * *$ \\
\hline 11 & NDRK-50001 & 93.67 & 0.26 & 105.95 & $6.37 * *$ & 22.35 & $1.60 *$ & 27.37 & $2.97 * *$ \\
\hline 12 & CSR - 23 & 94.00 & 1.26 & 87.77 & $9.18^{* *}$ & 22.50 & -0.92 & 26.78 & $-4.81 * *$ \\
\hline 13 & $\mathrm{CSR}-28$ & 79.00 & 0.70 & 103.50 & $-4.37 * *$ & 32.31 & -0.34 & 23.36 & $1.72 * *$ \\
\hline 14 & IR SST-N 27 & 89.33 & -0.63 & 65.10 & $-5.44 * *$ & 24.13 & 0.70 & 22 & -0.45 \\
\hline 15 & IR 74095 AC 64 & 88.00 & 0.48 & 81.30 & -2.16 & 14.29 & $-2.84 * *$ & 21.33 & $4.80 * *$ \\
\hline 16 & IR 72579-B-2R & 89.67 & 1.59 & 87.17 & $-10.92 * *$ & 16.64 & 0.11 & 20.43 & $0.85^{*}$ \\
\hline 17 & HPU-CIJ & 86.33 & $-1.96 * *$ & 91.37 & -0.14 & 22.32 & $1.69 * *$ & 20.36 & $2.50 * *$ \\
\hline \multirow[t]{4}{*}{18} & LD 183-4 & 95.33 & 0.04 & 81.30 & $10.12 * *$ & 31.94 & $3.06 * *$ & 21.7 & $1.63 * *$ \\
\hline & GM & 90.89 & & 88.15 & & 23.19 & & 22.83 & 0.40 \\
\hline & SE (gi) line & & 0.85 & & 0.60 & & 0.65 & & 1.94 \\
\hline & Tester & & & & & & & & \\
\hline 1 & Narendra Usar Dhan 2 & 93.00 & 0.06 & 92.71 & $2.97 * *$ & 31.95 & $1.54 * *$ & 29.14 & $0.44 * *$ \\
\hline 2 & Narendra Usar Dhan 3 & 92.33 & $-0.53 * *$ & 93.98 & $-1.41 * *$ & 29.04 & $-1.69 * *$ & 25.3 & $-0.62 * *$ \\
\hline \multirow[t]{3}{*}{3} & Narendra Usar Dhan 2009 & 91.67 & 0.16 & 83.98 & $-1.57 * *$ & 23.21 & 0.15 & 26.24 & 0.17 \\
\hline & GM & 92.33 & & 90.22 & & 28.06 & & 26.89 & 0.23 \\
\hline & SE(gi) tester & 0.49 & 0.22 & & 0.25 & & 0.27 & & 0.23 \\
\hline
\end{tabular}


Table.4 Mean performance and general combining ability (GCA) effects of parents (lines and testers) for Morphology and yield in rice under salinity condition

\begin{tabular}{|c|c|c|c|c|c|c|c|c|c|}
\hline \multirow[t]{2}{*}{ S.N. } & \multirow[t]{2}{*}{ Line } & \multicolumn{2}{|c|}{ Days to $50 \%$ flowering } & \multicolumn{2}{|c|}{ Plant height $(\mathrm{cm})$} & \multicolumn{2}{|c|}{ Flag leaf area $\left(\mathrm{cm}^{2}\right)$} & \multicolumn{2}{|c|}{ Grains yield /plant(g) } \\
\hline & & Mean & GCA & Mean & GCA & Mean & GCA & Mean & GCA \\
\hline 1 & NDRK-5014 & 99.00 & $3.60 * *$ & 79.82 & $2.55^{* *}$ & 19.31 & -0.45 & 24.42 & $3.60 * *$ \\
\hline 2 & NDRK-5016 & 98.67 & $2.34 * *$ & 84.42 & $1.72 * *$ & 19.20 & $1.16^{*}$ & 22.31 & $2.34 * *$ \\
\hline 3 & NDRK-5030 & 95.00 & $-7.28 * *$ & 87.29 & $-3.19 * *$ & 31.89 & $-1.88 * *$ & 24.73 & $-7.28 * *$ \\
\hline 4 & NDRK-5032 & 105.00 & 0.09 & 76.66 & $-5.18 * *$ & 17.75 & $-1.32 *$ & 13.05 & 0.09 \\
\hline 5 & NDRK-5035 & 99.67 & $3.16^{* *}$ & 86.43 & $1.46^{*}$ & 21.02 & $5.35 * *$ & 18.26 & $3.16 * *$ \\
\hline 6 & NDRK-5043 & 95.33 & -0.44 & 73.71 & $-7.84 * *$ & 22.53 & 0.39 & 11.28 & -0.44 \\
\hline 7 & NDRK-5062 & 104.67 & $-1.77 * *$ & 74.57 & 0.54 & 18.28 & $-1.13^{*}$ & 22 & $-1.77 * *$ \\
\hline 8 & NDRK-5071 & 98.67 & $-2.97 * *$ & 72.13 & $2.19 * *$ & 20.43 & $-2.41 * *$ & 23.47 & $-2.97 * *$ \\
\hline 9 & NDRK-5081 & 100.00 & $-2.81 * *$ & 84.13 & -0.77 & 24.25 & $-2.50 * *$ & 19.24 & $-2.81 * *$ \\
\hline 10 & NDRK-5092 & 97.67 & $-1.77 * *$ & 86.13 & $1.99 * *$ & 21.11 & -1.01 & 22.23 & $-1.77 * *$ \\
\hline 11 & NDRK-50001 & 100.33 & $3.99 * *$ & 81.73 & $7.67 * *$ & 30.62 & $-1.42 * *$ & 26.73 & $3.99 * *$ \\
\hline 12 & CSR - 23 & 99.33 & 0.67 & 82.89 & $4.21 * *$ & 31.24 & -0.13 & 24.95 & 0.67 \\
\hline 13 & CSR - 28 & 87.00 & $2.99 * *$ & 82.76 & $-6.08 * *$ & 16.46 & 0.79 & 22.44 & $2.99 * *$ \\
\hline 14 & IR SST-N 27 & 96.33 & $-6.11 * *$ & 63.40 & $-6.00 * *$ & 18.98 & -1.00 & 20.01 & $-6.11 * *$ \\
\hline 15 & IR 74095 AC 64 & 100.33 & $3.45 * *$ & 76.69 & 0.17 & 32.65 & $-1.53 * *$ & 20.68 & $3.45 * *$ \\
\hline 16 & IR 72579-B-2R & 92.33 & -0.67 & 81.16 & $-8.18 * *$ & 20.24 & -0.42 & 18.5 & -0.67 \\
\hline 17 & HPU-CIJ & 102.00 & $1.92 * *$ & 86.16 & $2.49 * *$ & 21.23 & $1.88 * *$ & 20.33 & $1.92 * *$ \\
\hline \multirow[t]{4}{*}{18} & LD 183-4 & 96.00 & $1.63 * *$ & 80.66 & $12.25 * *$ & 22.07 & $5.63 * *$ & 20.3 & $1.63 * *$ \\
\hline & GM & 98.19 & & 80.04 & & 22.74 & & 20.83 & \\
\hline & SE (gi) line & & 0.39 & & 0.64 & & 0.52 & & 0.39 \\
\hline & Tester & & & & & & & & \\
\hline 1 & Narendra Usar Dhan 2 & 97.67 & $-0.57 * *$ & 86.72 & $-0.89 * *$ & 24.72 & -0.18 & 25.1 & $-0.57 * *$ \\
\hline 2 & Narendra Usar Dhan 3 & 100.67 & $0.86 * *$ & 86.05 & -0.17 & 21.13 & $-0.79 * *$ & 25.19 & $0.86 * *$ \\
\hline \multirow[t]{3}{*}{3} & Narendra Usar Dhan 2009 & 99.00 & -0.29 & 81.25 & $1.07 * *$ & 19.72 & $0.97 * *$ & 24.95 & -0.29 \\
\hline & GM & 99.11 & & 84.67 & & 21.86 & & 25.08 & \\
\hline & SE(gi) tester & & 0.16 & & 0.26 & & 0.21 & & 0.16 \\
\hline
\end{tabular}

$*, * *$ Significant at $5 \%$ and $1 \%$ probability levels, respectively 
Table.5 Specific combining ability effects, mean performance, heterosis of crosses and general combining ability of Parents involved in crosses for grain yield per plant in rice under normal condition

\begin{tabular}{|c|c|c|c|c|c|}
\hline S.N. & Line & SCA & Mean & Standard heterosis & GCA \\
\hline 1 & IR SST N $27 \times$ Narendra Usar Dhan 2009 & $5.73 * *$ & 24.83 & $21.91 * *$ & $\mathrm{~L} \times \mathrm{L}$ \\
\hline 2 & IR 27579-B-2R × Narendra Usar Dhan 3 & $4.32 * *$ & 21.58 & 5.92 & $\mathrm{H} \times \mathrm{H}$ \\
\hline 3 & IR 74095 AC $64 \times$ Narendra Usar Dhan 3 & $4.04 * *$ & 24.75 & $21.50 * *$ & $\mathrm{H} \times \mathrm{H}$ \\
\hline 4 & NDRK $5071 \times$ Narendra Usar Dhan 2 & $4.01 * *$ & 27.3 & $34.04 * *$ & $\mathrm{H} \times \mathrm{A}$ \\
\hline 5 & CSR $23 \times$ Narendra Usar Dhan 2009 & $3.67 * *$ & 23.13 & $13.55 * *$ & $\mathrm{~L} \times \mathrm{A}$ \\
\hline 6 & NDRK $50001 \times$ Narendra Usar Dhan 3 & $3.44 * *$ & 33.42 & $64.05 * *$ & $\mathrm{H} \times \mathrm{H}$ \\
\hline 7 & NDRK $5071 \times$ Narendra Usar Dhan 3 & $3.41 * *$ & 24.29 & $19.23 * *$ & $\mathrm{H} \times \mathrm{H}$ \\
\hline 8 & LD 183-4 × Narendra Usar Dhan 3 & $2.69 * *$ & 23.42 & $14.96 * *$ & $\mathrm{H} \times \mathrm{H}$ \\
\hline 9 & NDRK $5032 \times$ Narendra Usar Dhan 3 & $2.54 * *$ & 30.43 & $49.40 * *$ & $\mathrm{~A} \times \mathrm{H}$ \\
\hline 10 & NDRK $5071 \times$ Narendra Usar Dhan 2009 & $2.11 * *$ & 19.07 & -6.4 & $\mathrm{H} \times \mathrm{L}$ \\
\hline 11 & NDRK $5014 \times$ Narendra Usar Dhan 2 & $2.07 * *$ & 30.19 & $48.21 * *$ & $\mathrm{H} \times \mathrm{A}$ \\
\hline 12 & HPU-CIJ × Narendra Usra Dhan 2009 & $1.66^{*}$ & 28.55 & $40.16^{* *}$ & $\mathrm{H} \times \mathrm{L}$ \\
\hline 13 & NDRK $5014 \times$ Narendra Usar Dhan 2009 & $1.53 *$ & 23.47 & $15.22 * *$ & $\mathrm{H} \times \mathrm{L}$ \\
\hline 14 & CSR $23 \times$ Narendra Usar Dhan 2 & $1.49 *$ & 31.13 & $52.84 * *$ & $\mathrm{~L} \times \mathrm{A}$ \\
\hline 15 & NDRK $5030 \times$ Narendra Usar Dhan 3 & $1.49 *$ & 23.67 & $16.18^{* *}$ & $\mathrm{~L} \times \mathrm{H}$ \\
\hline
\end{tabular}

$*, * *$ Significant at $5 \%$ and $1 \%$ probability levels, respectively

Table.6 Estimation of specific combining ability effects of significant crosses for grain yield and

Morphological traits in rice under normal condition

\begin{tabular}{|c|c|c|c|c|c|}
\hline S.N. & Line & Days to $50 \%$ flowering & Plant height $(\mathbf{c m})$ & Flag leaf area $\left(\mathrm{cm}^{2}\right)$ & Grains yield per plant (g) \\
\hline 1 & IR SST N $27 \times$ Narendra Usar Dhan 2009 & 1.96 & $-10.39 * *$ & -0.11 & $5.73^{* *}$ \\
\hline 2 & IR 27579-B-2R × Narendra Usar Dhan 3 & $4.04 * *$ & 1.15 & $-3.36 * *$ & $4.32 * *$ \\
\hline 3 & IR 74095 AC $64 \times$ Narendra Usar Dhan 3 & -0.11 & $-10.48 * *$ & $-4.37 * *$ & $4.04 * *$ \\
\hline 4 & NDRK $5071 \times$ Narendra Usar Dhan 2 & $-4.26 * *$ & $2.47 * *$ & 0.32 & $4.01 * *$ \\
\hline 5 & CSR $23 \times$ Narendra Usar Dhan 2009 & 1.56 & $8.65 * *$ & $4.64 * *$ & $3.67 * *$ \\
\hline 6 & NDRK $50001 \times$ Narendra Usar Dhan 3 & -0.26 & $-5.96 * *$ & 0.1 & $3.44 * *$ \\
\hline 7 & NDRK $5071 \times$ Narendra Usar Dhan 3 & -2.7 & $-12.02 * *$ & $-4.84 * *$ & $3.41 * *$ \\
\hline 8 & LD 183-4 × Narendra Usar Dhan 3 & -1.44 & $-3.67 * *$ & -0.16 & $2.69 * *$ \\
\hline 9 & NDRK $5032 \times$ Narendra Usar Dhan 3 & -0.19 & $-8.68 * *$ & -0.2 & $2.69 * *$ \\
\hline 10 & NDRK $5071 \times$ Narendra Usar Dhan 2009 & $-5.48 * *$ & $11.15 * *$ & $4.62 * *$ & $2.11 * *$ \\
\hline 11 & NDRK $5014 \times$ Narendra Usar Dhan 2 & 0.37 & -0.48 & $2.34 *$ & $1.53 *$ \\
\hline 12 & HPU-CIJ × NarendraUsraDhan 2009 & -2.74 & $-14.19 * *$ & $-4.75 * *$ & $1.66^{*}$ \\
\hline 13 & NDRK $5014 \times$ Narendra Usar Dhan 2009 & $5.93 * *$ & $-22.05 * *$ & $-3.22 * *$ & $1.53 *$ \\
\hline 14 & CSR $23 \times$ Narendra Usar Dhan 2 & -0.22 & $7.08 * *$ & $3.10 * *$ & $3.67 * *$ \\
\hline 15 & NDRK $5030 \times$ Narendra Usar Dhan 3 & $4.44 * *$ & $-3.75 * *$ & $8.16^{* * *}$ & $1.49 *$ \\
\hline
\end{tabular}


Table.7 Specific combining ability effects, mean performance, heterosis of crosses and general combining ability of parents involved in crosses for grain yield per plant in rice under salinity condition

\begin{tabular}{|c|c|c|c|c|c|}
\hline S.N. & Line & SCA & Mean & Standard heterosis & GCA \\
\hline 1 & NDRK $5071 \times$ Narendra Usar Dhan 2009 & $6.23 * *$ & 18.37 & $-14.73 * *$ & $\mathrm{~L} \times \mathrm{L}$ \\
\hline 2 & NDRK $5032 \times$ Narendra Usar Dhan 3 & $6.06 * *$ & 18.77 & $-12.88 * *$ & $\mathrm{~A} \times \mathrm{H}$ \\
\hline 3 & NDRK $5030 \times$ Narendra Usar Dhan 2009 & $3.87 * *$ & 23.05 & 7.01 & $\mathrm{~L} \times \mathrm{L}$ \\
\hline 4 & NDRK $5071 \times$ Narendra Usar Dhan 3 & $3.51 * *$ & 20.3 & -5.76 & $\mathrm{~L} \times \mathrm{L}$ \\
\hline 5 & NDRK $5071 \times$ Narendra Usar Dhan 2 & $3.20 * *$ & 23.47 & $8.94 *$ & $\mathrm{~A} \times \mathrm{H}$ \\
\hline 6 & CSR $23 \times$ Narendra Usar Dhan 3 & $2.92 * *$ & 22.67 & 5.23 & $\mathrm{~A} \times \mathrm{H}$ \\
\hline 7 & NDRK $50001 \times$ Narendra Usar Dhan 3 & $2.90 * *$ & 24.36 & $13.11 * *$ & $\mathrm{H} \times \mathrm{H}$ \\
\hline 8 & NDRK 5043 × Narendra Usar Dhan 3 & $2.22 * *$ & 24 & $11.42 * *$ & $\mathrm{~L} \times \mathrm{H}$ \\
\hline 9 & IR 27579-B-2R × Narendra Usar Dhan 2 & $1.96 * *$ & 25 & $16.06 * *$ & $\mathrm{~L} \times \mathrm{L}$ \\
\hline 10 & CSR $23 \times$ Narendra Usar Dhan 2009 & $1.67^{*}$ & 21.7 & 0.74 & $\mathrm{~A} \times \mathrm{L}$ \\
\hline 11 & HPU-CIJ × Narendra Usra Dhan 2009 & $1.46^{*}$ & 23.67 & $9.87 *$ & $\mathrm{H} \times \mathrm{L}$ \\
\hline
\end{tabular}

$*$, ** Significant at $5 \%$ and $1 \%$ probability levels, respectively

Table.8 Estimation of specific combining ability effects of significant crosses for grain yield and morphological traits in rice under salinity condition

\begin{tabular}{|c|c|c|c|c|c|}
\hline S.N. & Line & $\begin{array}{r}\text { Days to } 50 \% \\
\text { flowering } \\
\end{array}$ & Plant height $(\mathrm{cm})$ & Flag leaf area $\left(\mathrm{cm}^{2}\right)$ & $\begin{array}{r}\text { Grains yield per plant } \\
\text { (g) }\end{array}$ \\
\hline 1 & NDRK $5071 \times$ Narendra Usar Dhan 2009 & $6.23 * *$ & $7.94 * *$ & $3.17 * *$ & $6.23^{* *}$ \\
\hline 2 & NDRK $5032 \times$ Narendra Usar Dhan 3 & $6.06^{* *}$ & 0.08 & 1.59 & $6.06 * *$ \\
\hline 3 & NDRK $5030 \times$ Narendra Usar Dhan 2009 & $3.87 * *$ & 0.7 & 1.41 & $3.87 * *$ \\
\hline 4 & NDRK $5071 \times$ Narendra Usar Dhan 3 & $3.51 * *$ & $-6.12 * *$ & -1.16 & $3.51 * *$ \\
\hline 5 & NDRK $5071 \times$ Narendra Usar Dhan 2 & $3.20 * *$ & $7.67 * *$ & 1.38 & $3.20 * *$ \\
\hline 6 & NDRK $50001 \times$ Narendra Usar Dhan 3 & $2.92 * *$ & $2.60 *$ & $-2.06 *$ & $2.90 * *$ \\
\hline 7 & CSR $23 \times$ Narendra Usar Dhan 3 & $2.90 * *$ & $5.00 * *$ & 1.37 & $2.92 * *$ \\
\hline 8 & NDRK $5043 \times$ Narendra Usar Dhan 3 & $2.22 * *$ & $-2.50 *$ & -0.72 & $2.22 * *$ \\
\hline 9 & IR 27579-B-2R × Narendra Usar Dhan 2 & $1.96 * *$ & $9.37 * *$ & $-6.06 * *$ & $1.96 * *$ \\
\hline 10 & CSR $23 \times$ Narendra Usar Dhan 2009 & $1.67 *$ & $5.22 * *$ & 0.55 & $1.67 *$ \\
\hline 11 & HPU-CIJ × Narendra Usra Dhan 2009 & $1.46^{*}$ & -1.02 & $6.79 * *$ & $1.46 *$ \\
\hline
\end{tabular}


Fifteen crosses, IR SST N $27 \times$ Narendra Usar Dhan 2009, IR 27579-B-2R $\times$ Narendra Usar Dhan 3, IR 74095 AC $64 \times$ Narendra Usar Dhan 3, NDRK $5071 \times$ Narendra Usar Dhan 2, CSR $23 \times$ Narendra Usar Dhan 2009, NDRK 50001 $\times$ Narendra Usar Dhan 3, NDRK $5071 \times$ Narendra Usar Dhan 3, LD 183-4 × Narendra Usar Dhan 3, NDRK $5032 \times$ Narendra Usar Dhan 3, NDRK $5071 \times$ Narendra Usar Dhan 2009, NDRK $5014 \times$ Narendra Usar Dhan 2, HPU-CIJ × Narendra Usra Dhan 2009, NDRK $5014 \times$ Narendra Usar Dhan 2009, CSR $23 \times$ Narendra Usar Dhan 2 and NDRK $5030 \times$ Narendra Usar Dhan 3 exhibited significant and positive SCA effects for grain yield per plant, as well as for some morphological traits (Table 5 and 6 for normal condition). Perusal of data on the top hybrids having the highest SCA effects for grain yield per plant indicated that crosses involved high $\times$ high $($ IR 27579-B-2R $\times$ Narendra Usar Dhan 3, IR 74095 AC $64 \times$ Narendra Usar Dhan 3, NDRK $50001 \times$ Narendra Usar Dhan 3, NDRK $5071 \times$ Narendra Usar Dhan 3 and LD 183-4 × Narendra Usar Dhan 3), high $\times$ average (NDRK $5071 \times$ Narendra Usar Dhan 2 and NDRK $5014 \times$ Narendra Usar Dhan 2), high $\times$ low (NDRK $5071 \times$ Narendra Usar Dhan 2009, HPU-CIJ $\times$ NarendraUsraDhan 2009 and NDRK $5014 \times$ Narendra Usar Dhan 2009), average $\times$ high (NDRK $5032 \times$ Narendra Usar Dhan 3), low $\times$ high (NDRK $5030 \times$ Narendra Usar Dhan 3), low $\times$ average (CSR $23 \times$ Narendra Usar Dhan 2), low $\times$ low (IR SST N $27 \times$ Narendra Usar Dhan 2009) general combining parents. These results are in agreement with the findings of Ram et al., (1994), Dwivedi et al., (1999) and Devi et al., (2017). However, in self-pollinated crops, the additive $\times$ additive type of interaction is also fixable in later generations if the crosses showing high SCA effects involved parents which are good general combiners. Such crosses are usual to through some useful transgressive segregates in the breeding program for pedigree method of selection. Moreover, if the hybrids showing high SCA effects involved high $\times$ low general combiner parents (Table 5), the high SCA effect was attributed due to the interaction between positive effect allele from the good combiners and negative alleles from the poor combiners. The high yield from such crosses would be nonfixable in subsequent generations. If high $\times$ high GCA combiners would be involved in high heterosis, it would be due to interaction between positive $\times$ positive alleles and can be fixable in the succeeding generations if repulsion phase linkage were involved. Combining ability studies indicated that crosses with significant and positive SCA effects involved parents with high $\times$ high general combiner $9.25 \%$ and high $\times$ low with $5.55 \%$ in $\mathrm{F}_{1}$.

Thus, it is evident from the SCA effects of crosses for grain yield per plant were attributed almost equally due to dominance and epistasis gene interaction or due to additive $\times$ additive interaction. Young (1987) indicated that, in majority of the crosses, the high SCA effects of grain yield were attributed to dominance and epistasis effects under normal condition.

The estimates of standard heterosis ranged between -34.38 to $64.05 \%$. The top hybrids recording the high SCA effects for grain yield were shown to manifest high standard heterosis. The hybrids IR 27579-B-2R × Narendra Usar Dhan 3, IR 74095 AC $64 \times$ Narendra Usar Dhan 3, NDRK $50001 \times$ Narendra Usar Dhan 3, NDRK $5071 \times$ Narendra Usar Dhan 3, LD 183$4 \times$ Narendra Usar Dhan 3, NDRK $5071 \times$ Narendra Usar Dhan 2 and NDRK $5014 \times$ Narendra Usar Dhan 2 with high SCA effects for grain yield revealed significant standard heterosis and high mean performance involved both parents as high general combiner or one parent high and other as average combiner. High performance of such combinations is due to interaction of additive genes contributed by the parents. These crosses can be exploited through conventional breeding methods to isolate high-yielding pure lines. The higher heterosis in hybrids, NDRK $5071 \times$ Narendra Usar Dhan 2009, HPU-CIJ × Narendra Usra Dhan 2009, NDRK $5014 \times$ Narendra Usar Dhan 2009 and NDRK $5030 \times$ Narendra Usar Dhan 3 resulted from high $\times$ low or average $\times$ high and in crosses IR SST N $27 \times$ Narendra Usar Dhan 
2009 resulted from low $\times$ low general combiner, probably due to dominance and epistatic interaction with non-additive and non-fixable genetic component for grain yield. Random mating and selection among the segregates would lead to transgressive segregation in later generations. These hybrids can be exploited directly for hybrid breeding.

A closer examination of SCA effects of top crosses (Table 6) showing the maximum SCA effects for grain yield indicated that most of the crosses also displayed significant and high SCA effects for some morphological characters such as days to $50 \%$ flowering, plant height and flag leaf area. In general, the reports in the literature (Ram et al., 1994, Dwivedi et al., 1999 and Devi et al., 2017) also supported the present findings. Some crosses, specifically NDRK $50001 \times$ Narendra Usar Dhan 3, CSR $23 \times$ Narendra Usar Dhan 2,NDRK $5032 \times$ Narendra Usar Dhan 3, NDRK $5014 \times$ Narendra Usar Dhan 2 and HPU-CIJ $\times$ Narendra Usra Dhan 2009 exhibited high SCA, mean performance and standard heterosis were suggested for exploitation in the breeding program to create high-yielding pure lines with ideal plant type.

In saline condition, none of the crosses showed significant SCA effects in desirable direction for all the characters under study. Several crosses exhibited significant and desirable SCA effects for one or more characters but NDRK $5071 \times$ Narendra Usar Dhan 2009 emerged as good specific combination for all the characters.

Eleven crosses, NDRK $5071 \times$ Narendra Usar Dhan 2009, NDRK $5032 \times$ Narendra Usar Dhan 3, NDRK $5030 \times$ Narendra Usar Dhan 2009, NDRK $5071 \times$ Narendra Usar Dhan 3, NDRK $5071 \times$ Narendra Usar Dhan 2, CSR $23 \times$ Narendra Usar Dhan 3, NDRK $50001 \times$ Narendra Usar Dhan 3, NDRK $5043 \times$ Narendra Usar Dhan 3 and IR 27579-B-2R × Narendra Usar Dhan 2 showed highly significant and positive SCA effects for grains yield per plant while two crosses CSR $23 \times$ Narendra Usar Dhan 2009 and HPU-CIJ $\times$ Narendra Usra Dhan 2009 exhibited significant and positive
SCA effects for yield and morphological traits.

Perusal of data on the hybrids having the high SCA effects for grain yield per plant under saline condition (Table 7 and 8) indicated that crosses involved high $\times$ high $($ NDRK $50001 \times$ Narendra Usar Dhan 3), high $\times$ low (HPU-CIJ $\times$ Narendra Usar Dhan 2009 and NDRK $5043 \times$ Narendra Usar Dhan 3), and low $\times$ low (NDRK $5071 \times$ Narendra Usar Dhan 2, NDRK $5030 \times$ Narendra Usar Dhan 2009, NDRK $5071 \times$ Narendra Usar Dhan 3 and IR 27579-B-2R $\times$ Narendra Usar Dhan 2) general combining parent. These results are in agreement with the findings of Dwivedi et al., (1999).

The hybrids NDRK $50001 \times$ Narendra Usar Dhan 3, IR 27579-B-2R × Narendra Usar Dhan 2, NDRK $5043 \times$ Narendra Usar Dhan 3, HPUCIJ $\times$ Narendra Usar Dhan 2009 and NDRK $5071 \times$ Narendra Usar Dhan 2 with high SCA effects for grain yield revealed significant standard heterosis and per se performance and involved both parents as a high general combiner (NDRK $50001 \times$ Narendra Usar Dhan 3 ), one high and other low combiner (NDRK $5043 \times$ Narendra Usar Dhan 3 and HPU-CIJ $\times$ Narendra Usar Dhan 2009) and both low combiners (NDRK $5071 \times$ Narendra Usar Dhan 2, NDRK $5030 \times$ Narendra Usar Dhan 2009, NDRK $5071 \times$ Narendra Usar Dhan 3 and IR 27579-B-2R × Narendra Usar Dhan 2). The cross having both high general combiner parents can be exploited to isolate high-yielding pure lines with ideal plant type and crosses involving high $\times$ low and low $\times$ low general combining parents can be exploited directly for breeding hybrids with ideal plant type.

A closer examination of SCA effects of top crosses (Table 7) showing the maximum SCA effects for grain yield indicated that most of the crosses also displayed significant and high SCA effects for some morpho-physiological characters such as days to $50 \%$ flowering, plant height and flag leaf area. In general, the reports in the literature (Dwivedi et al., 1999) also supported the present findings. 


\section{References}

Arunachalam, V. 1974. The fallacy behind the use of modified line $\times$ tester design. Indian $J$. Genet., 34(2): 200-207.

Basavaraja, T., Asif, M., Mallikarjun, S.K., and Ganga Prasad, S. 2013. Variability heritability and genetic advance for yield and yield attributing characters in different local rice (Oryza sativa L.) cultivars. Asian Journal of Bio Science, 8(1): 60-62.

Burton, G.M., and de Vane, E.H. 1953. Estimating heritability in tall fescue (Festuca arundinacea) from replicated clonal material. Agron. J., 45: 471-481.

Devi, Archana, Kumari Preeti, Dwivedi Ranjan, Dwivedi Saket, Verma, O.P., Singh, P.K., and Dwivedi, D.K. 2017. Gene action and combining ability analysis for yield and yield contributing traits in rice (Oryza sativa L.) over environment. Journal of Pharmacognosy and Phytochemistry. 6(3): 662-671.

Dwivedi, D.K., Pandey, M.P., Pandey, S.K., and Rongbai, Li. 1999. Combining ability over environment in rice involving indica and tropical japonica lines. Oryza. 36(2): 101107.

Dwivedi, D.K., Pandey, M.P., Pandey, S.K., and Rongbai Li. 1999. Heterosis in inter and intra sub-specific crosses over three environments in rice. Euphytica. 99: 155165.

Fonseca, S. and Patterson, F. 1968. Hybrid vigour in a seven parent diallel cross in common winter wheat (Triticum aestivum L.). Crop Sci. 8: 85-88.

Hanson, C.H., Robinson, H.F., and Comstock, R.E. 1956. Biometrical studies of yield in segregating population of Korean Lespedeza. Agron. J. 45: 268-272.
Johnson, H.W., Robinson, H.F., and Comstock, R.E. 1955. Estimates of phenotypic and genotypic correlation in soybean and their implications in selection. Agron. J. 47: 477482.

Kempthorne, O. 1957. An introduction to genetic statistics. John Wiley and Sons Inc., New York.

Kumari Preeti, Devi Archana, Pandey, M.K., Dwivedi Saket, Dwivedi Ranjan, Mishra, K.K., Singh, P.K., Verma, O.P., Khan, N.A., and Dwivedi, D.K. 2017. Study on correlation coefficients and protein profiling in indigenous and exotic rice (Oryza sativa L.) under saline-alkali condition. Progressive research $-A n$ International Journal. 12(Special-1): 10851089.

Panse, V.G., and Sukhatme, P.V. 1967, 1994. Statistical methods for agricultural workers, $\mathrm{II}^{\text {nd }}$ Ed., 152-157. rice (Oryza sativa L.) for number of grains per panicle and grain yield. Oryza. 31: 1-15.

Ram, T., and Singh, R.M. 1994. Analysis of gene effects, combining ability and order of the parents in three-way crosses of rice (Oryza sativa L.) for number of grains per panicle and grain yield. Oryza. 31: 1-15.

Sathya R, and Jebaraj, S. 2013. Heritability and genetic advance estimates from three line rice hybrids under aerobic condition. International Journal of Agricultural Science and Research. 3(3): 69-74.

Singh, R.K., and Chaudhary, B.D. 1985. Biometrical methods in quantitative genetic analysis. Kalyani Publ., Ludhiana, New Delhi.

Young, L.P. 1987. Heterosis and combining ability over environments in relation to hybrid rice breeding. Ph.D. Thesis, University of the Philippines, Los Banos, Philippines.

\section{How to cite this article:}

Archana Devi, Preeti Kumari, Ranjan Dwivedi, Saket Dwivedi, O.P. Verma, P.K. Singh and Dwivedi, D.K. 2017. Studies on Heterosis and Combining Ability in Rice (Oryza sativa L.) for MorphoPhysiological Traits under Normal and Saline Conditions. Int.J.Curr.Microbiol.App.Sci. 6(8): 15581571. doi: https://doi.org/10.20546/ijcmas.2017.608.187 